\title{
Characteristics of taste and smell alterations reported by patients after starting treatment for lung cancer
}

\author{
Jenny McGreevy • Ylva Orrevall • Kerstin Belqaid • \\ Wendy Wismer • Carol Tishelman • \\ Britt-Marie Bernhardson
}

Received: 6 August 2013 / Accepted: 9 March 2014 /Published online: 22 April 2014

(C) Springer-Verlag Berlin Heidelberg 2014

\begin{abstract}
Purpose Taste and smell alterations (TSAs) in patients with lung cancer are poorly understood. This study investigates characteristics of TSAs when most severe, reported by patients after starting treatment for lung cancer.

Methods Data was collected regarding TSAs, symptoms, food intake and nutritional status through structured interviews using the Taste and Smell Survey, the Patient-Generated Subjective Global Assessment and 3-day food diaries. This data derives from a longitudinal project and the interview with each patient when TSAs were most severe was purposefully selected for analysis.

Results Sixty-one of the 89 patients reported TSAs, and the TSAs group were on average younger and more frequently smokers. Thirty-one patients reported symptoms impacting negatively on food intake, with $87 \%$ in the TSAs group and $13 \%$ in the no-TSAs group. Most commonly reported were loss of appetite, nausea and early satiety. Gender differences were seen with more women reporting stronger sensation(s) and more men
\end{abstract}

J. McGreevy $\cdot$ Y. Orrevall $\cdot$ K. Belqaid $\cdot$ C. Tishelman •

B.-M. Bernhardson

Department of Learning, Informatics, Management and Ethics,

Karolinska Institutet, Stockholm, Sweden

J. McGreevy $(\bowtie) \cdot$ Y. Orrevall $\cdot$ K. Belqaid $\cdot$ C. Tishelman •

B.-M. Bernhardson

R and D unit, Stockholms Sjukhem Foundation, PO box 122 30, 112

26 Stockholm, Sweden

e-mail: jenny.mcgreevy@virginmedia.com

W. Wismer

Department of Agricultural, Food and Nutritional Science, 4-10

Agriculture/Forestry Centre, University of Alberta, Edmonton, AB,

Canada reporting weaker sensation(s) and other changes. TSAs were described as affecting enjoyment of food and eating. A trend was seen where energy intakes declined with increasing TSAs. Energy intakes in the total study population were below recommended.

Conclusion TSAs varied in characteristics and interacted with other symptoms. Gender differences may highlight a need to investigate approaches for identification and management of TSAs in men and women. Patients reported TSAs impacting on food enjoyment, and the hypothesis that patients with higher TSS scores have lower nutritional intakes should be followed up with a larger study in the lung cancer population.

Keywords (4-6): taste and smell alterations · Lung neoplasm • Gender $\cdot$ Symptoms $\cdot$ Nutrition

\section{Introduction}

Enjoyment of food comes from the sight, smell, taste and social context of a meal. Together with the texture and temperature of food, taste and smell form the sensory concept of flavour [1]. When taste and smell functions are altered, food preferences may change and food aversions develop which may significantly reduce the pleasure of eating [2].

Taste and smell alterations (TSAs) have been found to be common and distressing symptoms in patients with cancer during chemotherapy [3, 4], radiotherapy [5] and in advanced stages of cancer [6, 7]. The capacity to perceive taste sensations is known to influence food choices [8], and TSAs have been associated with decreased nutrient intake and greater weight loss in patients with advanced cancer $[6,7]$. 
Taste detection and recognition thresholds of basic tastes (salt, sweet, sour and bitter) have been measured in patients with cancer using clinical [9] and electrical tests [10]. Smell changes in the absence of taste changes have been less well studied [11]. However, the complexities of taste and smell perception and interaction with food intake and food enjoyment cannot be determined by clinical measurements of taste and smell thresholds [6]. Global questions on general symptom questionnaires have been used to study self-reported TSAs in cancer [12] but do not investigate characteristics of such changes. A more extensive questionnaire, the Taste and Smell Survey (TSS) [13], has been used by a Canadian research group to investigate characteristics of self-reported TSAs in patients with advanced cancer $[6,7,14]$ and has been recently translated into Swedish [15].

Although lung cancer is the most common cancer in the world and the fourth most common cancer among men and women in Sweden [16], little is known about the characteristics of TSAs experienced in this patient group or relation of TSAs to other symptoms and nutritional intake and status. Treatment options for lung cancer depend on type and stage of disease and patients' general health [17] and include surgery, chemotherapy, radiotherapy, target therapy or combinations of these. Many patients present in advanced disease stages and report clusters of symptoms including altered taste sensation, which continue during the course of the disease [18].

Although common and distressing symptoms in patients with cancer, TSAs are reportedly not given the same attention as other symptoms in the clinical cancer care setting with healthcare staff citing lack of evidencebased guidelines for detection and management of TSAs as an explanation [19]. A deeper understanding of TSAs in patients with lung cancer may therefore facilitate development of evidence-based guidelines for identification and management of TSAs.

The primary aims of this study were therefore to investigate (1) the characteristics of TSAs when most severe as reported by patients after start of treatment for lung cancer, (2) how TSAs relate to symptoms and nutritional intake and status and (3) how patients describe their TSAs. In order to obtain a rich data set, we selected the time point for each patient after the start of treatment when reported TSAs were most severe thus framing the data in relation to degree of TSAs. We also first explore if and how patients reporting and not reporting TSAs differ.

\section{Methods}

Study design and procedure

Data derives from the longitudinal Taste and Smell project which investigates TSAs in patients with lung or gastrointestinal cancer. Approval was received from the Regional Research Ethical Review Board in Stockholm, Sweden, prior to starting the project. Patients with suspected primary lung cancer or diagnosed with gastrointestinal cancer were recruited consecutively over 18 months (2011-2012) from a university hospital. Swedish-speaking patients $\geq 18$ years living in Stockholm were eligible for inclusion if cognitively able to complete interviews and never diagnosed with head/neck cancer, which is known to be strongly associated with TSAs. Patients treated for or diagnosed with another cancer within the previous 6 months were excluded. Data were obtained from structured face-to-face interviews using four questionnaires. Interviews were held at a location chosen by the patient, often in their homes or at the hospital. Patients received information about the project and gave informed consent on recruitment. The interviewer read the questions from the questionnaires and documented patients' verbal responses using direct quotes in open items where possible. Detailed field notes were written after each interview. The first interview was held close to diagnosis and prior to the initiation of cancer treatment (T1), followed by three interviews at 2 -month intervals (T2, T3, T4).

In this study, data from patients who had started treatment for primary lung cancer were analysed regarding TSAs, demographic factors, nutritional status and intake and symptom burden. Data were derived using the instruments described below.

\section{Data collection measures}

Characteristics of TSAs were investigated using the Taste and Smell Survey (TSS) [13], translated into Swedish for use in the Taste and Smell project [15]. The TSS is a 16-item questionnaire which allows patients to self-report TSAs and describe experiences of TSAs and impact on food choices. Patients were asked at each interview to compare present taste and smell sensations on how they were before initiation of the diagnostic process for lung cancer. Responses to six items asking patients to report presence or absence of TSAs and changes in sensation of basic tastes and smell 
were used to dichotomise patients into the groups 'TSAs' and 'no-TSAs'. Patients were categorised in the TSAs group if they (1) responded positively to any of the four items with yes/no responses regarding taste or smell changes or (2) indicated a change in intensity of any of the sensations of salt, sweet, sour and bitter tastes and sense of smell. Four of these items have follow-up open-ended questions where patients can elaborate further on their TSAs. Descriptions of TSAs and reported changes in sensation were used to investigate characteristics.

Responses from the TSS can also be used to generate a score from $0-16$ [13]. To investigate nutritional intake in relation to TSS scores we utilised a different stratification method based on TSS scores: $0-4=$ no to mild TSAs, 5 $-9=$ moderate TSAs and $10=16=$ severe TSAs.

Patients received a food diary at each interview with information about how to record food and beverage intake in detail over 3 days close to interview date including time of consumption and amounts consumed using standard measures supplied at T1. Completed food diaries were collected by interviewers or returned by post and ambiguities in records discussed with the patient where possible. Each patient's food intakes were calculated from food diaries by one of two dietitians using the software program Dietist XP developed by 'Kost och Näringsdata' which builds on the food database of the Swedish National Food Agency. A reference table [20] was used to estimate serving sizes and weight of food portions, and a detailed audit trail was kept regarding calculations. Average daily energy and protein intakes were calculated per kilogram using body weight measured at interview. Patients were also asked if they prepared their own meals.

Responses given in box 3 of the Swedish version of the scored Patient-Generated Subjective Global Assessment (PG-SGA) [21, 22] were used to assess if any of the 12 symptoms had impacted on patients' food intake over the previous 2 weeks. In the interview, patients were also asked to self-report current weight and recall their weight 6 months prior to the interview. Patients were also weighed using calibrated weighing scales.

Information about patients' diagnosis and treatment were obtained from medical records with patients' informed consent. Patients were asked about their smoking habits which were categorised as non-smoker (includes occasional smokers), smokers, and former smokers (not smoked in $>1$ year) [23].

\section{Data analysis}

As our aim was to obtain maximum data about characteristics of TSAs and their relationship to food intake, we purposefully chose data from the interview after the start of treatment with the highest TSS scores and with corresponding food diary for the TSAs group. For the no-TSAs group, the first interview after the start of the treatment with corresponding food diary was selected. Table 1 shows how long after the start of the treatment the chosen interviews were for each group.

Descriptive statistics were used to describe the patient population. Statistical analyses were performed using as appropriate $t$ test, chi-square test and Fisher's exact test for comparisons of TSAs and no-TSAs groups regarding age, gender, smoking and symptoms. All tests were two-tailed and significance value was set at $\leq 0.05$. The IBM-SPSS Statistics program version 20 was used.

Patients' responses to open-ended questions were analysed inductively using content analysis [24]. Each response was divided into meaning units based on words and phrases relating to characteristics of TSAs which were then grouped into six categories. To ensure reliability, three independent coders categorised random lists of meaning units with the final average Cohen's Kappa for inter-rater agreement of all six categories being 0.89 (range 0.79-0.92).

\section{Results}

Description of study sample

We first describe patients reporting TSAs (TSAs group) and those not reporting TSAs (no-TSAs group) to explore if and how these groups differ regarding demographics, disease type and stage, and treatment modality (Table 1). In the sample of 89 patients, 61 reported TSAs in the interviews after starting treatment for lung cancer. Statistically significant differences between TSAs and no-TSAs groups were seen with the TSAs group being on average younger and more frequently smokers than nonsmokers or former smokers. There were no significant differences between the TSAs and the no-TSAs groups in relation to gender, type of lung cancer, stage of disease, treatment ongoing at time of interview and type of treatment before interview. 
Table 1 Characteristics of study population

\begin{tabular}{|c|c|c|c|c|}
\hline & Characteristics & $\begin{array}{l}\text { Patients reporting } \\
\text { TSAs } \\
n=61(69)\end{array}$ & $\begin{array}{l}\text { Patients reporting } \\
\text { no-TSAs } \\
n=28(31)\end{array}$ & $\begin{array}{l}\text { Study population } \\
n=89\end{array}$ \\
\hline \multicolumn{5}{|l|}{ Gender } \\
\hline & Men $n(\%)$ & $25(63)$ & $15(37)$ & 40 \\
\hline & Women $n(\%)$ & $36(73)$ & $13(27)$ & 49 \\
\hline \multicolumn{5}{|l|}{ Age at interview ${ }^{\mathrm{a}}$} \\
\hline & Mean (SD) & $66(9)$ & $71(6)$ & $67(9)$ \\
\hline \multicolumn{5}{|l|}{ Smoking habits ${ }^{\mathrm{b}}$} \\
\hline & Non-smoker n (\%) & $5(63)$ & $3(38)$ & 8 \\
\hline & Smoker $n(\%)$ & $31(89)$ & $4(11)$ & 35 \\
\hline & Former smoker $n(\%)$ & $25(54)$ & $21(46)$ & 46 \\
\hline \multicolumn{5}{|l|}{ Type of lung cancer } \\
\hline & NSCLC & $54(71)$ & $22(29)$ & 76 \\
\hline & SCLC & 2 & 1 & 3 \\
\hline & Other (carcinoid, mesothelioma, multiple tumours) & 5 & 3 & 8 \\
\hline & Unverified & 0 & 2 & 2 \\
\hline \multicolumn{5}{|l|}{ Stage of disease } \\
\hline & Stages I-II & $27(71)$ & $11(29)$ & 38 \\
\hline & Stage III & $11(65)$ & $6(35)$ & 17 \\
\hline & Stage IV & $23(68)$ & $11(32)$ & 34 \\
\hline \multicolumn{5}{|l|}{ Treatment before interview: $n(\%)$} \\
\hline & Surgery & $13(57)$ & $10(43)$ & 23 \\
\hline & Chemo, surgery+chemo & $29(71)$ & $12(29)$ & 41 \\
\hline & RT, SRT & 5 & 2 & 7 \\
\hline & Target & 2 & 1 & 3 \\
\hline & Concomitant RT/chemo & 9 & 2 & 11 \\
\hline & Sequential RT/chemo & 3 & 1 & 4 \\
\hline Treatment ongoing at interview & & $24(63)$ & $14(37)$ & 38 \\
\hline Number of days since treatment start & Mean (min-max) & $74(9-191)$ & $45(7-148)$ & $65(7-191)$ \\
\hline
\end{tabular}

$T S A s$ taste and smell alterations, $N S C L C$ non-small cell lung cancer, $S C L C$ small cell lung cancer, $R T$ radiotherapy, SRT stereotactic radiation therapy, Chemo chemotherapy, $S D$ standard deviation

Significant difference ( $p$ value $\leq 0.05$ ) between TSAs and no-TSAs groups regarding: ${ }^{\mathrm{a}}$ age, ${ }^{\mathrm{b}}$ number of smokers compared to former smokers

Completed food diaries were received from 64 of the 89 patients $(72 \%)$ with a higher response frequency $(82 \%)$ from the no-TSAs than the TSAs group (67\%), although this difference was not statistically significant. Despite the small sample size precluding our ability to draw firm conclusions, we explored the relationship between energy and protein intakes in relation to TSS scores and found a trend where intakes declined with increasing scores. Average energy intake for all 64 patients who completed food diaries was $26 \mathrm{kcal} / \mathrm{kg} /$ day and average protein intake $1.0 \mathrm{~g} / \mathrm{kg} /$ day. Weights were reported by 88 of the 89 patients and indicated an average weight loss of $4 \%$ during the 6 months prior to interview (Table 2). An average 6-month weight loss of $6 \%$ was reported by patients reporting both TSAs and loss of appetite $(n=18)$ (data not shown). In the full sample of 89 patients, $80 \%$ of women and $30 \%$ of men reported that they were responsible for or took some role in preparing their meals with no significant difference between TSAs and no-TSAs groups (data not shown).

Thirty-one of the 89 study patients reported one or more symptoms impacting negatively on food intake using the scored PG-SGA, with $87 \%$ of these in the TSAs group and $13 \%$ in the no-TSAs group. Symptoms most commonly reported were loss of appetite, nausea and early satiety. There was a statistically significant difference between numbers reporting loss of appetite with TSAs compared with no-TSAs, although no statistically significant differences were found regarding nausea and early satiety with TSAs compared with no-TSAs (Table 3).

\section{Characteristics of TSAs}

Based on responses to TSS, the 61 patients reporting TSAs were classified into four groups, with three groups regarding 
Table 2 Nutritional intakes and 6-month weight change based on stratified TSS scores

\begin{tabular}{|c|c|c|c|c|c|}
\hline & & $\begin{array}{l}\text { No-mild TSAs } \\
\text { (scores } 0-4) \\
n=34(14 \text { food } \\
\quad \text { diaries missing) }\end{array}$ & $\begin{array}{l}\text { Moderate TSAs } \\
\text { (scores 5-9) } \\
n=26 \text { ( } 7 \text { food diaries missing) }\end{array}$ & $\begin{array}{l}\text { Severe TSAs } \\
\text { (scores } 10-16) \\
n=4 \text { (4 food diaries missing) }\end{array}$ & $\begin{array}{l}\text { Total } \\
n=64 \text { ( } 25 \text { food } \\
\quad \text { diaries missing })\end{array}$ \\
\hline $\begin{array}{l}\text { Energy intake } \\
\quad(\mathrm{kcal} / \mathrm{kg} \mathrm{BW})\end{array}$ & Mean \pm SD & $27 \pm 9$ & $26 \pm 8$ & $18 \pm 8$ & $26 \pm 9$ \\
\hline $\begin{array}{l}\text { Protein intake } \\
\quad(\mathrm{g} / \mathrm{kg} \mathrm{BW})\end{array}$ & Mean \pm SD & $1.1 \pm 0.3$ & $1.0 \pm 0.3$ & $0.7 \pm 0.3$ & $1.0 \pm 0.3$ \\
\hline \multirow[t]{2}{*}{ Energy intake (kcal) } & Mean \pm SD & $1,888 \pm 485$ & $1,796 \pm 353$ & $1,440 \pm 945$ & $1,823 \pm 476$ \\
\hline & & $\begin{array}{l}\text { No-mild TSAs } \\
n=48\end{array}$ & $\begin{array}{l}\text { Moderate TSAs } \\
n=32 \text { (one weight missing) }\end{array}$ & $\begin{array}{l}\text { Severe TSAs } \\
n=8\end{array}$ & $\begin{array}{l}\text { Total } \\
n=88 \text { (one weight missing) }\end{array}$ \\
\hline \multirow{3}{*}{$\begin{array}{l}\text { 6-month weight } \\
\text { change }(\%)\end{array}$} & Mean \pm SD & $-3 \pm 6$ & $-5 \pm 6$ & $-3 \pm 9$ & $-4 \pm 6$ \\
\hline & Max loss & -14 & -23 & -12 & -23 \\
\hline & Max gain & +9 & +8 & +12 & +12 \\
\hline
\end{tabular}

TSAs taste and smell alterations, min minimum, max maximum, $k c a l$ kilocalories, $K g$ kilogram, $g$ gram, BW body weight

reported changes in intensity of sensations of salt, sweet, sour and bitter tastes and sense of smell as follows: (1) stronger sensation, (2) weaker sensation (includes cannot perceive tastes or smell), (3) mixed sensation changes (some tastes or smell stronger and some weaker) and a final group reporting other TSAs with no changes in sensation intensity (see Table 4 for examples). All patients also described and exemplified their TSAs in response to the open-ended questions.

Table 3 Symptoms impacting negatively on food intake in TSAs and noTSAs groups reported using scored PG-SGA

\begin{tabular}{llll}
\hline & $\begin{array}{l}\text { Patients } \\
\text { reporting TSAs } \\
n=61\end{array}$ & $\begin{array}{l}\text { Patients reporting } \\
\text { no-TSAs } \\
n=28\end{array}$ & $\begin{array}{l}\text { Total } \\
\text { patients } \\
n=89\end{array}$ \\
\hline $\begin{array}{l}\text { Total number of patients } \\
\text { reporting symptoms }\end{array}$ & 27 & 4 & 31 \\
$\begin{array}{l}\text { impacting negatively on } \\
\text { food intake* }\end{array}$ & & & \\
$\begin{array}{l}\text { Symptoms } \\
\text { Loss of appetite* }\end{array}$ & 19 & 2 & \\
$\begin{array}{l}\text { Early satiety } \\
\text { Nausea }\end{array}$ & 14 & 2 & 21 \\
Constipation & 10 & 1 & 16 \\
Vomiting & 6 & - & 11 \\
Pain & 5 & - & 6 \\
Swallowing problems & 4 & 1 & 5 \\
Dry mouth & 3 & - & 5 \\
Diarrhea & 2 & 1 & 4 \\
Mouth sores & - & - & 2 \\
$\quad$ Other & 6 & - & \\
e.g. cough, feeling & & - & \\
depressed, fatigue & & & \\
\hline
\end{tabular}

TSAs taste and smell alterations, $P G-S G A$ patient-generated subjective global assessment

${ }^{*} p$ value $\leq 0.05$
Statistically significant gender differences were seen in TSAs with more women reporting stronger sensation(s) and more men reporting weaker sensation(s) and other TSAs (Fig. 1a). There was no statistically significant relationship between changes in sensation and age, smoking or symptoms (data not shown) or between gender and age or smoking habits.

Reported changes in sensation of each of the four individual basic tastes and smell were further analysed in relation to gender. Differences were seen, in particular with a greater proportion of women reporting TSAs experiencing stronger compared to weaker sour and bitter tastes as well as sense of smell (Fig. 1b) and a greater proportion of men reporting TSAs experiencing all tastes as weaker compared to stronger. There was a statistically significant difference by gender with more women reporting stronger smell sensation.

Content analysis of responses to open-ended questions provided more in-depth information about patients' descriptions of TSAs. All the patients in the TSAs group responded to openended questions by describing their TSAs. Patient responses were read thoroughly, and meaning units, that is discrete words or phrases used by patients to relate key thoughts or concepts in their descriptions of TSAs, were highlighted. The responses generated 216 meaning units which were then grouped into the six categories shown in Table 4.

The largest number of meaning units related to reduced liking of foods and reduced enjoyment of eating, with some patients expressing revulsion at particular foods. It was not possible to distinguish patterns in foods reported to work well. Other symptoms were often described in relation to TSAs. When asked to describe taste changes, a number of patients also talked about loss of appetite, early satiety or nausea, whilst when asked to describe smell changes, nausea was mentioned. Patients reported changes in sensation of food, cooking and chemical smells. Women generally tended to contribute more meaning units than men. 
Table 4 Categories of TSAs described in open-ended questions number (no.) and proportion of contributed meaning units by gender are shown

\begin{tabular}{|c|c|c|c|}
\hline \multirow[b]{2}{*}{ Examples of meaning units in each category } & \multirow{2}{*}{$\begin{array}{l}\text { Total no. } \\
\text { of meaning units } \\
n=216\end{array}$} & \multicolumn{2}{|c|}{$\begin{array}{l}\text { No. and proportion of meaning } \\
\text { units by gender } n(\%)\end{array}$} \\
\hline & & $\begin{array}{l}\text { Meaning units } \\
\text { contributed by men } \\
n=61\end{array}$ & $\begin{array}{l}\text { Meaning units } \\
\text { contributed by women } \\
n=155\end{array}$ \\
\hline $\begin{array}{l}\text { Reports a change in general taste or a change in general intensity of taste or } \\
\text { a change in intensity of any of the four basic tastes (salt, sweet, sour, bitter) } \\
\text { without describing an emotional response to the change } \\
\text { 'Everything tastes different for example cordials and fizzy drinks' } \\
\text { 'All fruit tastes the same' } \\
\text { 'Cereal and yoghurt now have a distorted taste' } \\
\text { 'Meatballs, for example, have no taste' } \\
\text { 'Nothing has any taste' } \\
\text { 'Taste of spices just does not come through' } \\
\text { 'Sour is too sour' } \\
\text { 'Sweet tastes sweeter' } \\
\text { 'Feel that sweet things do not have as much taste, for example fruit' } \\
\text { 'More sensitive to salt' } \\
\text { 'Need to add more salt and sugar to food' }\end{array}$ & 42 & $14(33)$ & $28(67)$ \\
\hline $\begin{array}{l}\text { Reports reduced liking of specific foods or reduced enjoyment of eating } \\
\text { 'Juice tastes sharp, have drunk it though it does not taste nice' } \\
\text { 'I normally like pear cider but now it just tastes of sugar' } \\
\text { 'Red wine tastes disgusting' } \\
\text { 'Milk is disgusting' } \\
\text { 'Coffee is not nice anymore' } \\
\text { 'Everything tasted disgusting and the same' } \\
\text { 'Nothing tastes nice' } \\
\text { 'I cannot think about drinking water' } \\
\text { 'Sweetcorn tastes disgusting although I usually like it' } \\
\text { 'I cannot stand coffee or eggs now' } \\
\text { 'I hate chicken now' } \\
\text { 'What I sometimes think will taste nice is not nice' }\end{array}$ & $\begin{array}{l}68 \\
\text { Examples of specific foods: } \\
\text { Coffee, } 19 \\
\text { Beer/wine/whisky, } 5 \\
\text { Meat, } 4 \\
\text { Water, } 3 \\
\text { Milk, } 3\end{array}$ & $18(26)$ & $50(74)$ \\
\hline $\begin{array}{l}\text { Specifies particular foods that work well } \\
\text { 'Home made grape juice was nice' } \\
\text { 'Salty biscuits work better' } \\
\text { 'I can only drink lemon tea' } \\
\text { 'I have lived on fruit and vegetables, nothing else works' } \\
\text { 'All food that is tart works well' } \\
\text { 'It is easier with sweet things' } \\
\text { 'Could only eat neutral tasting foods like wafer biscuits } \\
\text { and cooked vegetables' }\end{array}$ & 16 & $3(19)$ & $13(81)$ \\
\hline $\begin{array}{l}\text { Describes other symptoms related to eating problems e.g. appetite, } \\
\text { nausea, early satiety, swallowing, oral problems. } \\
\text { 'Everything tastes different because I am feeling nauseous' } \\
\text { 'Nothing tastes good - its related to appetite' } \\
\text { 'Want to eat but I feel full quickly' } \\
\text { 'Do not have a good appetite, the longing and desire for } \\
\text { food is not there' } \\
\text { 'A persistent underlying feeling of nausea affects my sense of taste' } \\
\text { 'Everything tastes different because of feeling nauseous' }\end{array}$ & $\begin{array}{l}27 \\
\text { Examples of symptoms: } \\
\text { Appetite, } 12 \\
\text { Nausea, } 6 \\
\text { Vomiting, } 3 \\
\text { Oral problems, } 2\end{array}$ & $6(22)$ & $21(78)$ \\
\hline $\begin{array}{l}\text { Describes taste changes using comparisons with metal, paper, wood, } \\
\text { medicine or using other likenesses. } \\
\text { 'Everything tastes metallic, even water' } \\
\text { 'Everything tastes like paper' } \\
\text { 'Tastes of medicine' } \\
\text { 'Like everything is wrapped in cotton' } \\
\text { 'After radiotherapy everything tasted like old tree stumps' }\end{array}$ & $\begin{array}{l}14 \\
\text { Metallic, } 9 \\
\text { Paper, } 1 \\
\text { Wood, } 1 \\
\text { Cotton, } 1 \\
\text { Insipid, } 1 \\
\text { Medicine, } 1\end{array}$ & $7(50)$ & $7(50)$ \\
\hline $\begin{array}{l}\text { Describes changes in sense of smell (both increased and decreased sensitivity) } \\
\text { 'Feel nauseous from the smell of food frying nearby' } \\
\text { 'For a period everything smelt of chemotherapy' } \\
\text { 'I smell a musty odour at home that my husband does not' } \\
\text { 'I can feel nauseous of a smell that I am used to' } \\
\text { 'Could not tolerate the smell of perfume, fried food, deodorant' } \\
\text { 'Eat meat but it smells awful when its being cooked' } \\
\text { 'Very sensitive for the smell of after-shave and perfume, feel nauseous' }\end{array}$ & 49 & $13(27)$ & $36(73)$ \\
\hline
\end{tabular}

no. number, TSAs taste and smell alterations 
(a)

Men $n=40$

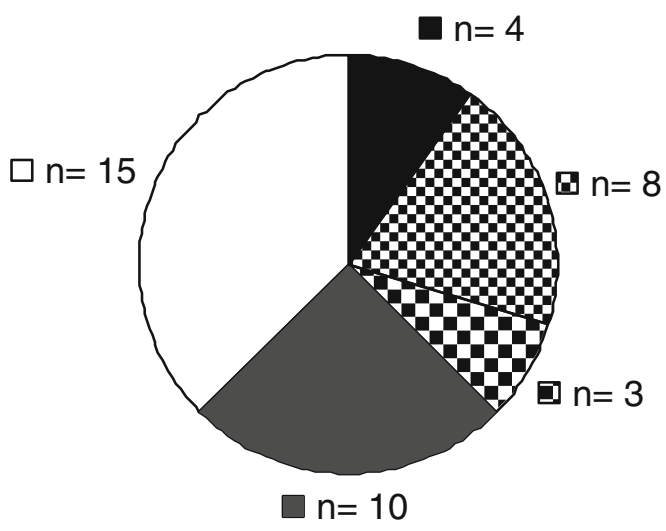

Women $n=49$

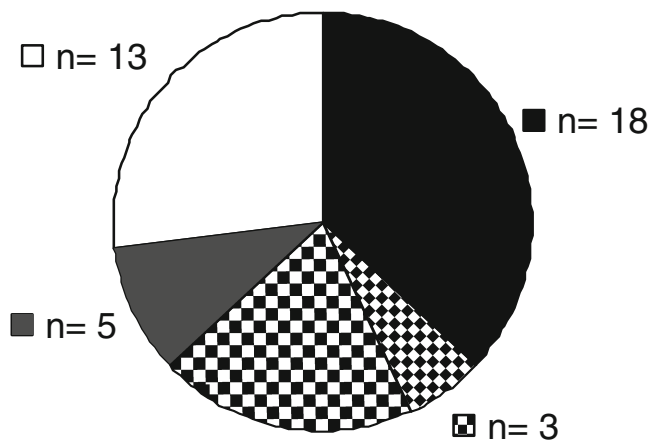

$\square \mathrm{n}=10$ stronger sensation

Weaker sensation (includes cannot perceive)

$\checkmark$ mixed sensation changes(some tastes and/or smell stronger, some weaker)

$\square$ other TSAs (no changes in sensation intensity)

$\square$ no TSAs

stronger sensation

W weaker sensation (includes cannot perceive)

$\checkmark$ mixed sensation changes(some tastes and/or smell stronger, some weaker)

$\square$ other TSAs (no changes in sensation intensity)

$\square$ no TSAs

(b)

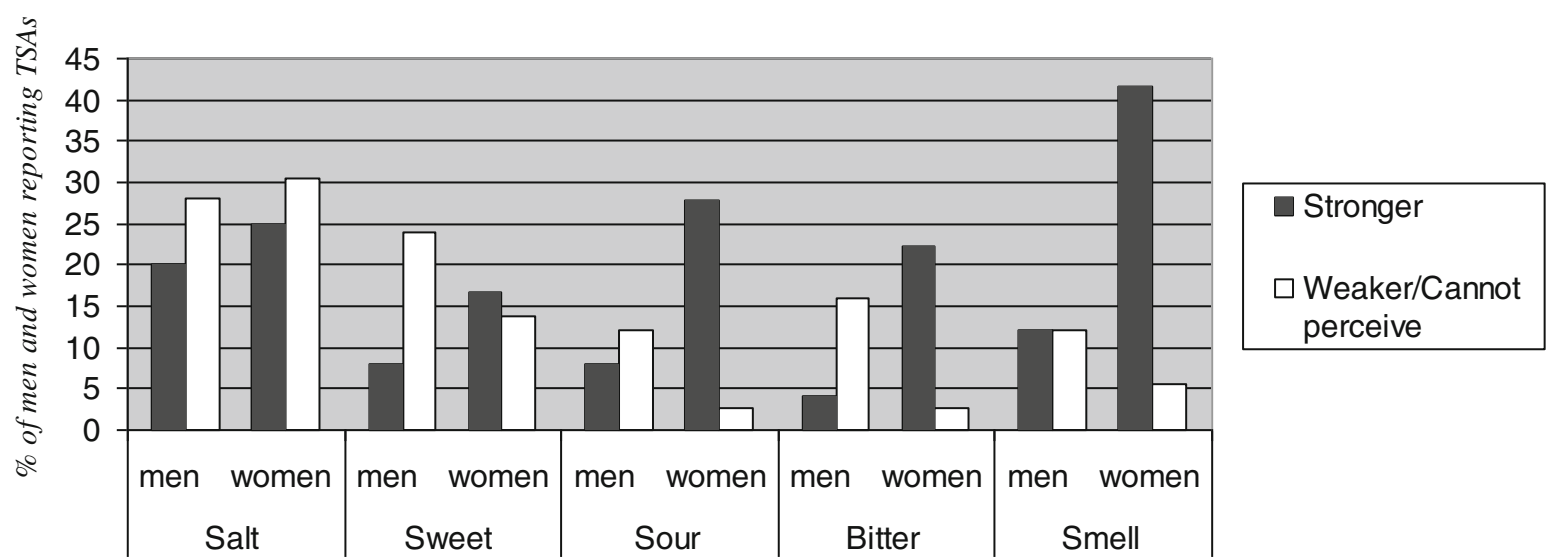

Fig. 1 a Number of patients reporting changes in sensation of taste and smell by gender. Abbreviations: TSAs taste and smell alterations. b Reported changes in intensity of basic tastes and smell by gender. Frequencies of reported changes in intensity of basic tastes and smell are expressed as the percentage of men $(n=25)$ and the percentage of women $(n=36)$ reporting TSAs. Abbreviations: TSAs taste and smell alterations 


\section{Discussion}

In this study, we sampled the time point when TSS scores were highest and food diary completed for each person after start of treatment. Treatment trajectories were different depending on the patients' stage of disease and type of lung cancer. Patients in the TSAs group were younger and more patients reported being smokers. Statistically significant differences were seen in characteristics of TSAs reported by men and women regarding changes in sensation of basic tastes and smell. Loss of appetite, early satiety and nausea were more often reported as interfering with eating by patients reporting TSAs and were also described in relation to TSAs in openended questions suggesting inter-relationships between these symptoms. Women contributed proportionally more meaning units than men when describing their TSAs in open-ended questions. More women than men in both the TSAs and noTSAs groups described being responsible for or involved in the preparation of their meals. Reduced food enjoyment was frequently reported in relation to TSAs. Intakes of energy and protein were sub-optimal for those patients who completed food diaries and tended to decrease with increased TSS scores. There is a wide variation in time span from the start of treatment to the interview in the TSAs group. As we selected the interview when TSAs were most pronounced during the study period, this may reflect the tendency for it to take time before TSAs reached a peak in our sample. A previous study has reported onset of TSAs at up to 10 weeks after start of chemotherapy [25]. Another factor may be lack of an earlier interview that was fully complete.

Reasons for gender differences in our results regarding changes in sensation and descriptions of TSAs are unclear, but possibilities include physiological differences in taste and smell perception or differences in men's and women's relationship to food, its preparation and eating. Other possible explanations could be how men and women interpret and prioritise TSAs or even gender differences in ability or readiness to talk about their perceptions of TSAs. Many patients in this study belong to a generation where socially constructed gender roles involve preparation of food as a traditionally female role. Studies of elderly men in the USA have reported that men describe themselves as lacking skills in meal planning and cooking as their wives were or had been responsible for meals, and describe eating as a means of staying alive and keeping the body strong rather than as a pleasure [26, 27]. In a study in Oslo, men of working age described food and eating habits as not being a special focus for them and therefore not reflected upon [28].

Reported gender differences in food choice in the USA and Sweden indicate that women are more likely to eat more fruit, vegetables and fibre; less meat and limit salt intake [29, 30]. These differences in relationship to food choice, preparation and eating may lead to men and women having a different vocabulary and ease of expression when describing food and its tastes and smells.

Canadian studies of patients with heterogeneous cancer diagnoses in palliative care $[6,7]$ found that TSAs were associated with lower energy intakes and higher 6-month weight loss. The lung cancer patients in this study frequently described TSAs relating to reduced enjoyment of food and eating. Although not able to be fully tested within the scope of this study, these explorative data lead us to hypothesise that nutritional intakes decrease with increasing TSS scores. On average, patients had lost weight over 6 months prior to the interview with greatest losses in patients reporting both TSAs and loss of appetite, which may indicate that patients with multiple symptoms are at greater risk of weight loss.

Malnutrition with involuntary loss of weight and muscle mass are cancer-related problems associated with impaired treatment outcomes, treatment toxicity, increased risk of complications and reduced survival [31-34]. Recommended energy requirements of patients with cancer are estimated at 30$35 \mathrm{kcal} / \mathrm{kg} /$ day for ambulatory patients [35]. Minimum recommended protein requirements are estimated at $1 \mathrm{~g} / \mathrm{kg} /$ day [35]. Patients completing food diaries in this study had calculated mean energy intakes below these recommended levels, although mean protein intakes met minimum recommended intakes. In food record studies, underreporting is a common form of respondent bias. Although not as prevalent, over reporting also occurs [36], and this patient group may over report in an attempt to give a more favourable impression of declining food intakes. Not all patients completed food diaries, and the slightly lower response frequency from the TSAs group may be due to a higher symptom burden affecting their ability to carry out the task.

As previously noted, healthcare staff in the clinical cancer care setting do not focus on TSAs as much as other symptoms citing a need for evidence-based guidelines to improve management of TSAs [19]. Tishelman [37] has hypothesised that problems may be more readily legitimised by patients and staff if there are strategies available to deal with them. Corner and Bailey [38] consider it important that healthcare staff focus on helping the patient articulate and interpret the meaning of problems and show acceptance of patients' experiences. This can be a way of developing strategies for management of problems. Characteristics of TSAs and interaction with other symptoms present important challenges for healthcare staff in the nutritional care of this patient group. Helping patients to describe TSAs may be benefited by a common terminology so that characteristics can be identified and differentiated from other symptoms as management strategies may vary.

There are a number of strengths and limitations in this study. Patients are comparable with the lung cancer population in Stockholm regarding age [23] but differ in that we have a slightly higher proportion of women in our sample (55\%). A higher proportion of patients were classified as stages I-II lung 
cancer (38\%) and proportionately fewer classified as stage IV (34\%) than in the lung cancer register statistics for Sweden [23]. Patients selected for this study therefore represent a 'healthier' sample of those affected by this serious disease.

Data was obtained through face-to-face interviews, which has the advantage of improving response rate and reducing misunderstandings. However communication between interviewer and respondent may affect responses [39] and interview bias may occur if the respondent seeks to satisfy the interviewer with responses [40].

It should be noted that although the sample size of characteristic groups are small, we found statistically significant results. The strength of this study in comparison to other studies of TSAs in cancer is that we investigate TSAs when most severe in a sample representing the wide variety of treatment trajectories in the clinical care of patients with lung cancer rather than assess TSAs in relation to treatment. This design enabled us to gain a deeper understanding of the characteristics of TSAs when most severe.

\section{Conclusion}

Our results contribute important information regarding characteristics of TSAs when most pronounced during the study period after start of treatment for lung cancer. The variations in characteristics reported and the complex interplay with other symptoms may contribute to the difficulty healthcare staff have in focusing on TSAs, indicating that a screening method to differentiate between characteristics of TSAs and other symptoms may be required to facilitate symptom specific advice. Gender differences in reported TSAs may highlight a need to investigate the vocabulary and approaches used for identification and management of TSAs in men and women. Patients reported TSAs impacting on food enjoyment and the hypothesis that patients with higher TSS scores have lower nutritional intakes should be followed up with a larger study investigating TSAs and nutritional intake and status in the lung cancer population.

Acknowledgments Economic support was provided by the Swedish Research Council and the Strategic Research Programme in Health Care Sciences.

Disclosures None.

\section{References}

1. Boltong A, Keast R, Aranda S (2012) Experiences and consequences of altered taste, flavour and food hedonics during chemotherapy treatment. Support Care Cancer 20:2765-2774
2. Bellisle E (2003) Why should we study human food intake behaviour? Nutr Metab Cardiovasc Dis 13:189-193

3. Bernhardson BM, Tishelman C, Rutqvist LE (2009) Taste and smell changes in patients receiving cancer chemotherapy: distress, impact on daily life, and self-care strategies. Cancer Nurs 32:45-54

4. Zabernigg A, Gamper EM, Giesinger JM, Rumpold G, Kemmler G, Gattringer K, Sperner-Unterweger B, Holzner B (2010) Taste alterations in cancer patients receiving chemotherapy: a neglected side effect? Oncologist 15:913-920

5. Yamashita H, Nakagawa K, Tago M, Nakamura N, Shiraishi K, Eda M, Nakata H, Nagamatsu N, Yokoyama R, Onimura M, Ohtomo K (2006) Taste dysfunction in patients receiving radiotherapy. Head Neck J Sci Spec Head Neck 28:508-516

6. Brisbois TD, de Kock IH, Watanabe SM, Baracos VE, Wismer WV (2011) Characterization of chemosensory alterations in advanced cancer reveals specific chemosensory phenotypes impacting dietary intake and quality of life. J Pain Symptom Manag 41:673-683

7. Hutton JL, Baracos VE, Wismer WV (2007) Chemosensory dysfunction is a primary factor in the evolution of declining nutritional status and quality of life in patients with advanced cancer. J Pain Symptom Manag 33:156-165

8. Snyder DJ, Bartoshuk LM (2009) Epidemiological studies of taste function discussion and perspectives. In: Finger TE (ed) International Symposium on Olfaction and Taste. Blackwell Publishing, Oxford, pp 574-580

9. Ovesen L, Hannibal J, Sorensen M (1991) Taste thresholds in patients with small-cell lung-cancer. J Cancer Res Clin Oncol 117:70-72

10. Yamagata T, Nakamura Y, Yamagata Y, Nakanishi M, Matsunaga K, Nakanishi H, Nishimoto T, Minakata Y, Mune M, Yukawa S (2003) The pilot trial of the prevention of the increase in electrical taste thresholds by zinc containing fluid infusion during chemotherapy to treat primary lung cancer. J Exp Clin Cancer Res 22:557-563

11. Bernhardson BM, Tishelman C, Rutqvist LE (2009) Olfactory changes among patients receiving chemotherapy. Eur J Oncol Nurs 13:9-15

12. Kirkova J, Walsh D, Rybicki L, Davis MP, Aktas A, Tao J, Homsi J (2010) Symptom severity and distress in advanced cancer. Palliat Med 24:330-339

13. Heald AE, Pieper CF, Schiffman SS (1998) Taste and smell complaints in HIV-infected patients. AIDS 12:1667-1674

14. Bernhardson BM, Olson K, Baracos VE, Wismer WV (2012) Reframing eating during chemotherapy in cancer patients with chemosensory alterations. Eur J Oncol Nurs 16:483-490

15. McGreevy J, Orrevall Y, Belqaid K, Bernhardson B-M (2013) Reflections on the process of translation and cultural adaptation of an instrument to investigate taste and smell changes in adults with cancer. Scand JCaring Sci. doi:10.1111/scs.12026/pdf

16. The National Board of Health and Welfare (2012) cancer incidence in Sweden 2011

17. Onkologisk Centrum (2010) Regional Cancer Centre Stockholm Gotland. Clinical care program for lung cancer

18. Gift AG, Stommel M, Jablonski A, Given W (2003) A cluster of symptoms over time in patients with lung cancer. Nurs Res 52:393-400

19. Boltong A, Keast R, Aranda S (2011) Talking about taste: How do oncology clinicians discuss and document taste problems? Cancer Forum 35(2):81-87

20. KF och ICA provkök (2011) Mått för mat. ICA Bokförlag

21. Bauer J, Capra S, Ferguson M (2002) Use of the scored PatientGenerated Subjective Global Assessment (PG-SGA) as a nutrition assessment tool in patients with cancer. Eur J Clin Nutr 56:779-785

22. Persson C, Sjoden PO, Glimelius B (1999) The Swedish version of the patient-generated subjective global assessment of nutritional status: gastrointestinal vs urological cancers. Clin Nutr 18:71-77

23. Regionalt Onkologiskt Centrum (2011) Nationellt register för lung cancer: Lung cancer i Sverige - Redovisning av material för år 20022009. Regional Oncology Centre 
24. Hsieh HF, Shannon SE (2005) Three approaches to qualitative content analysis. Qual Health Res 15:1277-1288

25. Bernhardson BM, Tishelman C, Rutqvist LE (2008) Self-reported taste and smell changes during cancer chemotherapy. Support Care Cancer 16:275-283

26. Keller HH, Gibbs A, Wong S, Vanderkooy PD, Hedley M (2004) Men can cook! Development, implementation, and evaluation of a senior men's cooking group. J Nutr Elder 24:71-87

27. Moss SZ, Moss MS, Kilbride JE, Rubinstein RL (2007) Frail men's perspectives on food and eating. J Aging Stud 21:314-324

28. Roos G, Wandel M (2005) "I eat because I'm hungry, because its good, and to become full": everyday eating voiced by male carpenters, drivers, and engineers in contemporary Oslo. Food Foodways 13(1-2):169-180

29. Amcoff E, Edberg A, Lindroos A, Nälsén C, Pearson M, E WL (2012) Riksmaten-Adults 2010-11. Dietary habits and nutrient intake in Sweden. National Food Agency, Sweden

30. Wardle J, Haase AM, Steptoe A, Nillapun M, Jonwutiwes K, Bellisle F (2004) Gender differences in food choice: the contribution of health beliefs and dieting. Ann Behav Med Publ Soc Behav Med 27:107-116

31. Baracos VE, Reiman T, Mourtzakis M, Gioulbasanis I, Antoun S (2010) Body composition in patients with non-small cell lung cancer: a contemporary view of cancer cachexia with the use of computed tomography image analysis. Am J Clin Nutr 91:1133S-1137S

32. Fearon K, Strasser F, Anker SD, Bosaeus I, Bruera E, Fainsinger RL, Jatoi A, Loprinzi C, MacDonald N, Mantovani G, Davis M,
Muscaritoli M, Ottery F, Radbruch L, Ravasco P, Walsh D, Wilcock A, Kaasa S, Baracos VE (2011) Definition and classification of cancer cachexia: an international consensus. Lancet Oncol 12: 489-495

33. Ross PJ, Ashley S, Norton A, Priest K, Waters JS, Eisen T, Smith IE, O'Brien MER (2004) Do patients with weight loss have a worse outcome when undergoing chemotherapy for lung cancers? Br J Cancer 90:1905-1911

34. Tewari N, Martin-Ucar AE, Black E, Beggs L, Beggs FD, Duffy JP, Morgan WE (2007) Nutritional status affects long term survival after lobectomy for lung cancer. Lung Cancer 57:389-394

35. Arends J, Bodoky G, Bozzetti F, Fearon K, Muscaritoli M, Selga G, van Bokhorst-de van der Schueren MAE, von Meyenfeldt M, Zurcher G, Fietkau R, Aulbert E, Frick B, Holm M, Kneba M, Mestrom HJ, Zander A (2006) ESPEN guidelines on enteral nutrition: non-surgical oncology. Clin Nutr 25:245-259

36. Gibson R (2005) Principles of nutritional assessment. Oxford University Press, New York

37. Tishelman C (1993) Who cares? Patients' descriptions of age-related aspects of cancer and care in Stockholm. Cancer Nursing 16:270-282

38. Corner J, Bailey C (2008) Cancer nursing care in context. Blackwell Publishing Ltd., Oxford

39. Ongena YP, Dijkstra W (2007) A model of cognitive processes and conversational principles in survey interview interaction. Appl Cogn Psychol 21:145-163

40. Krosnick JA (1999) Survey research. Annu Rev Psychol 50:537-567 